\title{
Ensino de dança na escola: desafios e perspectivas na visão de professores
}

\author{
Teaching of dance in school: challenges and \\ perspectives in the vision of teachers \\ La enseñanza de la danza en la escuela: desafios y \\ perspectivas en la visión de los profesores \\ CeCília Silvano Batalha (iDa \\ GISELI BARRETO DA CRUZ
}

\section{Resumo}

O presente estudo trata de uma pesquisa, desenvolvida no Estado do Rio de Janeiro, cujo objetivo consistiu em compreender como professores com formação superior em dança, que atuaram ou estão atuando na educação básica, no contexto da escola pública, concebem o ensino de dança e, além disso, o que fazem (se fazem) a favor da sua inserção enquanto área de conhecimento no currículo escolar. A abordagem se atém a parte dos resultados obtidos, detendo-se especificamente nos aspectos referentes à inserção da dança no currículo escolar, considerando quatro eixos analíticos: i - produção do conhecimento por meio do corpo; ii possibilidade de trabalhar questões sociais e humanas; iii - questões multiculturais presentes na inserção da dança no currículo; iv - dificuldades estruturais para o ensino de dança na escola. O referencial teórico baseia-se em Cochran-Smith e Lytle (1999; 2002), Gauthier (2006) e Schön (2000); Canen/Ivenicki (2012; 2014); Marques (2010a; 2011; 2012); Strazzacappa (2010); Strazzacappa e Morandi (2012). Metodologicamente, adota-se a análise documental e a entrevista semiestruturada.

\footnotetext{
a Universidade Federal do Rio de Janeiro (PPGE/UFRJ), Rio de Janeiro, RJ, Brasil. Mestre em Educação (PPGE/UFRJ), e-mail: ceciliasilvano@yahoo.com.br

b Universidade Federal do Rio de Janeiro (UFRJ), Rio de Janeiro, RJ, Brasil. Doutora em Educação, e-mail: giselicruz@ufrj.br
} 
Os resultados da pesquisa indicam que a inserção da dança no currículo é um desafio evidente para os professores, ainda que se reconheça que este ensino possa ser um espaço potente para a produção do conhecimento por meio do corpo, possibilitando uma formação mais abrangente.

Palavras-chave: Currículo. Ensino de Dança na escola. Formação de professores.

\begin{abstract}
This paper is a research report with the objective of understanding how teachers with higher education degree in Dance, who worked or are currently working with public basic education, perceive the teaching of Dance and, beyond that, what they do (if they do) to favor their insertion in school curriculum. The article focuses on some of the results obtained with the study, focusing specifically on aspects related to the insertion of dance in the school curriculum, considering four analytical axes: $i$ - production of knowledge through the body; ii - possibility to work on social and human issues; iii - multicultural issues present in the insertion of dance in the curriculum; iv - structural difficulties for teaching dance in school. The theoretical referential includes Cochran-Smith \& Lytle (1999; 2002), Gauthier (2006); Schön (2000); Canen/Ivenicki (2012; 2014); Marques (2010; 2011; 2012) and Strazzacappa (2010; 2012). Methodologically, it was operated with documental analysis and semi-structured interview. The results of the research indicate that the insertion of the dance in curriculum is an evident challenge for the teachers, even if it is recognized that this teaching can be a powerful place for the knowledge production through the body, making a more comprehensive education possible.
\end{abstract}

Keywords: Curriculum. Teaching of Dance in School. Teacher Education.

\title{
Resumen
}

Se trata de un informe de investigación cuyo objetivo era comprender cómo los maestros con la educación superior en danza, que trabajaron o trabajan en la educación básica pública, que conciben la enseñanza de la danza y, por otra parte, lo que hacen (si lo hacen) a favor de su inclusión en el programa de estudios. El artículo focaliza parte de los resultados obtenidos con el estudio, deteniéndose específicamente en los aspectos referentes a la inserción de la danza en el currículo escolar, considerando cuatro ejes analíticos: $i$ - producción del conocimiento por medio del cuerpo; ii - posibilidad de trabajar cuestiones sociales y humanas; iii - cuestiones multiculturales presentes en la inserción de la danza en el currículo; iv - dificultades estructurales para la enseñanza de la danza en la escuela. El marco teórico basado en Cochran-Smith y Lytle (1999; 2002), Gauthier (2006); Schön (2000); Canen/Ivenicki (2012; 2014); Marques (2010; 2011; 2012) y Strazzacappa (2010; 2012). Metodológicamente operado con el análisis de documentos y entrevista semi-estructurada. Los resultados del estudio indican que la inclusión de la danza en el plan de estudios es un claro desafío para los profesores, aunque se reconoce 
que esta educación puede ser un espacio de gran alcance para la producción de conocimiento a través del cuerpo, que permite una formación más completa.

Palabras clave: Currículo. Enseñanza de la danza en la escuela. Formación de profesores.

\section{Introdução}

$\mathrm{O}$ artigo que ora se apresenta à leitura situa-se na interface das áreas de Arte, Didática, Currículo e Formação de Professores, com foco no ensino de dança. Embora o ensino de arte seja garantido pela atual Lei de Diretrizes e Bases da Educação Nacional (n ${ }^{\circ}$ 9.394/96), sua presença no currículo escolar não é algo constante.

Dentro do currículo escolar, a dança pode ser abordada no componente curricular da arte, ou no componente curricular da educação física e também a partir de propostas interdisciplinares advindas de outras áreas de conhecimento. Recorrentemente, o que se observa é que nas aulas de educação física a dança aparece, sobretudo, como atividade prática, ligada ao conjunto de atividades rítmicas expressivas, por ser considerada parte da cultura corporal do movimento, e, nas aulas de arte, a dança aparece incorporada em suas dimensões artísticas e estéticas, sem deixar de atribuir relevância à parte prática e a questões que envolvem a diversidade cultural.

De acordo com Soter (2016), essa dupla presença pode gerar equívocos, pois o fato de a dança poder ser abordada nas aulas de educação física pode fazer pensar que não há necessidade de incorporá-la como uma área de conhecimento no componente curricular arte. Entretanto, se formos analisar cuidadosamente, veremos que a forma como ela é concebida em cada campo é diferente. Nas aulas de educação física, a dança pode ser tratada dentro do conjunto das atividades rítmicas e expressivas; desse modo ela é considerada um conteúdo da cultura corporal do movimento, em que prevalecem aspectos voltados para a prática. Nas aulas de arte, a dança é tratada como área de conhecimento e, para além da perspectiva prática, há também uma vertente artística, em que prevalecem aspectos artísticos e estéticos, 
como a estesia e a fruição. Neste sentido, tal como temos discutido (BATALHA; CRUZ, 2018), a inserção da dança no currículo escolar está marcada por ambiguidade, fato que talvez possa prejudicar esse ensino. Por outro lado, revela a riqueza peculiar da dança, visto que ela pode ocorrer em duas áreas de conhecimento distintas e com concepções diferentes. Para Marques (2010a) as querelas entre a dança/arte e a dança/educação física ainda estão longe de serem resolvidas no contexto escolar e nos meios acadêmicos.

Em termos legais, a promulgação da Lei de Diretrizes e Bases da Educação Nacional, $\mathrm{n}^{\mathrm{o}}$ 9.394, de 20 de dezembro de 1996, considera a arte componente curricular obrigatório na educação básica: "O ensino da arte especialmente em suas expressões regionais constituirá componente curricular obrigatório, nos diversos níveis da educação básica, de forma a promover o desenvolvimento cultural dos alunos" (artigo 26, parágrafo $2^{\circ}$, redação dada pela Lei n 12.287 , de 2010). Ainda que a lei tenha representado um avanço para o ensino da arte, até então entendido como atividade educativa, não deixa claro quais áreas de conhecimento compõem a arte, se tornando frágil do ponto de vista da declaração do direito, deixando de garantir a presença da dança no currículo da educação básica junto ao ensino da arte. Felizmente, essa configuração legal chega ao fim com a aprovação da Lei $n^{\circ} 13.278$, em maio de 2016, que altera a redação dos parágrafos $2^{\circ}$ e $6^{\circ}$ do artigo 26 da LDB (9.394/96), passando a prever que o ensino de artes visuais, dança, música e teatro tornem-se obrigatórios. O prazo para que os sistemas de ensino implantem as mudanças, incluída a formação dos professores em número suficiente para atuar na educação básica, é de cinco anos.

Importa salientar um contexto de mudanças e rupturas que evidencia avanços na busca pela consolidação da dança enquanto área de conhecimento, o que é possível observar, em especial, pelo aumento na oferta de cursos superiores de dança no Brasil $^{1}$, uma vez que em 2002 havia cerca de 30 cursos no país e hoje, de acordo com levantamento realizado ${ }^{2}$, existem 32 cursos de licenciatura em dança e 14 de

\footnotetext{
1 Destacamos como fator determinante para o aumento do número de cursos superiores de dança no país a implantação do Programa de Apoio a Planos de Reestruturação e Expansão das Universidades Federais - REUNI, especificamente nas Instituições Públicas Federais.

2 Fonte: <http://emec.mec.gov.br/>. Acesso em: jan 2019.
} 
bacharelado em dança, totalizando um quantitativo de 46 cursos superiores de dança oferecidos em instituições federais, estaduais e particulares.

A partir da contribuição de autores como Marques (2010a, 2011, 2012) e Strazzacappa e Morandi (2010, 2012), o ensino de dança, enquanto elemento formativo e, portanto, área de conhecimento no campo da arte, é visto como um espaço potente no currículo em que o conhecimento possa ser trabalhado/construído por meio do corpo, e com isso, possa-se promover uma rede de relações entre a arte, o ensino e a sociedade. Neste sentido, o professor graduado em dança torna-se sujeito fundamental, visto que sua formação e inserção na escola pública é potente para qualificar as práticas educativas.

Diante do exposto, desenvolvemos uma pesquisa com o objetivo de compreender como professores com formação superior em dança (bacharel ou licenciado), que atuaram ou estão atuando na educação básica pública, concebem o ensino de dança e, além disso, o que fazem (e se fazem) a favor da inserção da dança no currículo escolar. Para tanto, algumas questões mobilizaram a pesquisa: quem são e onde estão esses professores? Quais metodologias e estratégias sustentam suas aulas? O que diferencia o ensino de dança na escola das aulas de dança oferecidas em outros espaços formativos? Como ela pode vir a se relacionar com outras áreas de conhecimento do currículo?

O caminho metodológico percorrido para a construção dos dados orientou-se pela análise documental, contemplando entrevista semiestruturada. A análise se deteve em documentos que consideramos norteadores para o ensino de arte/dança, buscando identificar, a partir de eixos analíticos, convergências e divergências presentes nos textos analisados. Nossas evidências foram construídas, ainda, a partir de entrevistas realizadas com nove depoentes: oito professores de arte/dança que atuam (ou já atuaram) com este ensino em escolas públicas do Estado do Rio de Janeiro e uma professora universitária, referência na área de dança e de formação de professores de dança no Brasil.

Diante dos depoimentos, buscamos compreender o que os professores entrevistados pensam sobre a inserção da dança no currículo escolar e como ela pode se relacionar com outras áreas de conhecimento do currículo, sobretudo, em uma perspectiva interdisciplinar. No que se refere à atuação desse professor, procuramos 
identificar quais saberes docentes eles mobilizam para ensinar dança na escola, em que medida a diversidade cultural está presente e, ainda, se há interlocução com a perspectiva multicultural.

Neste relato apresentaremos parte dos resultados obtidos com o estudo, detendo-nos especificamente nos aspectos referentes à inserção da dança no currículo escolar, focalizando quatro eixos analíticos: i - produção do conhecimento por meio do corpo; ii - possibilidade de trabalhar questões sociais e humanas; iii - questões multiculturais presentes na inserção da dança no currículo; vi - dificuldades estruturais para o ensino de dança na escola.

\section{Aspectos teóricos metodológicos}

Mills (1982) destaca que o objetivo da pesquisa consiste, também, em solucionar desacordos e dúvidas sobre fatos, tornando assim as discussões sobre determinado tema mais frutíferas. Nessa perspectiva, ele defende que a pesquisa seja desenvolvida como uma artesania, incentivando que todo pesquisador/intelectual deve dispor de postura artesã, definindo a peça, traçando o seu desenho, colhendo os meios de sua criação, organizando o material, compondo sua produção. Foi assim, sob sua inspiração, que buscamos organizar os meios que consideramos adequados para chegarmos aos objetivos deste estudo.

Concebemos e desenvolvemos uma pesquisa de base qualitativa, voltada para o estudo de um tema (o ensino de dança na escola) na perspectiva dos significados que as pessoas (professores) a ele conferem. Nesse sentido, o caminho metodológico orientou-se para a visão do sujeito investigado, por meio da realização de entrevista semiestruturada. Mas, para situar a visão no contexto do problema, antes mesmo de realizar as entrevistas, percebemos a necessidade de recorrer a outras estratégias metodológicas. Assim, definimos a realização da análise documental de legislação sobre ensino de dança e de referentes curriculares para fundamentar a discussão contextualizada do tema e, ainda, a realização de entrevistas com os professores localizados no âmbito do campo de pesquisa definido, para mapear as suas visões sobre concepções e práticas de ensino de dança.

Nessa direção, ancoramo-nos na realização de entrevista semiestruturada, que "[...] combina perguntas fechadas e abertas, em que o entrevistado tem a possibilidade 
de discorrer sobre o tema em questão sem se prender à indagação formulada" (MINAYO, 2013, p. 64). No intuito de conhecer os pontos de vista dos atores sociais envolvidos com o ensino de dança na escola básica, esse recurso metodológico mostrou-se fundamental, uma vez que forneceu os dados básicos para o desenvolvimento e compreensão de relações entre os sujeitos e sua situação. Como etapas de trabalho percorridas visando à realização das entrevistas, inicialmente, identificamos professores com formação superior em dança (bacharel ou licenciado), com atuação em escolas públicas de educação básica. Os municípios em que os professores atuam, ou já atuaram, com o ensino de dança são Mesquita, Niterói, Nova Friburgo e Rio de Janeiro (SME), e também no Estado do Rio de Janeiro (SEEDUC e FAETEC). Ainda, entrevistou-se uma pesquisadora que é referência na área de dança no Brasil. Assim, o corpo de sujeitos da pesquisa se constitui de nove depoentes, oito professores de dança, dentre eles, seis licenciados, um bacharel, um bacharel com complementação pedagógica e uma pesquisadora. Por tratar-se de um grupo minoritário, à medida que notamos recorrência das respostas, decidimos encerrar nossa busca. O quadro abaixo sumariza as principais características de identificação dos sujeitos da pesquisa.

Quadro 1 - Sujeitos participantes da pesquisa

\begin{tabular}{|c|c|c|c|c|c|c|}
\hline $\begin{array}{l}\text { Identificação } \\
\text { do sujeito }\end{array}$ & $\begin{array}{l}\text { Sex } \\
0\end{array}$ & $\begin{array}{l}\text { Tipo de } \\
\text { Formação }\end{array}$ & $\begin{array}{l}\text { Instituição de } \\
\text { Formação }\end{array}$ & $\begin{array}{l}\text { Rede de } \\
\text { Ensino }\end{array}$ & $\begin{array}{l}\text { Área de } \\
\text { Atuação }\end{array}$ & $\begin{array}{l}\text { Tempo de } \\
\text { Atuação }\end{array}$ \\
\hline MES & $\mathrm{F}$ & $\begin{array}{l}\text { Licenciatura em } \\
\text { Dança }\end{array}$ & $\begin{array}{l}\text { Faculdade da } \\
\text { Cidade }\end{array}$ & Mesquita & Arte & 6 anos \\
\hline NIT & $\mathrm{F}$ & $\begin{array}{l}\text { Licenciatura em } \\
\text { Dança }\end{array}$ & $\begin{array}{l}\text { Faculdade da } \\
\text { Cidade }\end{array}$ & Niterói & $\begin{array}{l}\text { Educação } \\
\text { Física }\end{array}$ & 10 anos \\
\hline SME & $\mathrm{F}$ & $\begin{array}{l}\text { Licenciatura em } \\
\text { Dança }\end{array}$ & $\begin{array}{l}\text { Faculdade da } \\
\text { Cidade }\end{array}$ & $\begin{array}{l}\text { Rio de } \\
\text { Janeiro }\end{array}$ & Arte & 6 anos \\
\hline FRI & $\mathrm{F}$ & $\begin{array}{l}\text { Bacharelado em } \\
\text { Dança }\end{array}$ & UFRJ & $\begin{array}{l}\text { Nova } \\
\text { Friburgo }\end{array}$ & Dança & 2 anos \\
\hline SEEDUC1 & $\mathrm{M}$ & $\begin{array}{l}\text { Licenciatura em } \\
\text { Dança }\end{array}$ & UFRJ & Estado RJ & Arte & 1 ano \\
\hline FAETEC1 & $\mathrm{F}$ & $\begin{array}{l}\text { Bacharelado em } \\
\text { Dança com } \\
\text { complem. ped. }\end{array}$ & UFRJ & Estado RJ & Dança & 6 anos \\
\hline FAETEC2 & $\mathrm{F}$ & $\begin{array}{l}\text { Licenciatura em } \\
\text { Dança }\end{array}$ & $\begin{array}{l}\text { Faculdade da } \\
\text { Cidade }\end{array}$ & Estado RJ & Arte Dança & 6 anos \\
\hline SEEDUC2 & $\mathrm{M}$ & $\begin{array}{l}\text { Licenciatura em } \\
\text { Dança }\end{array}$ & $\begin{array}{l}\text { Faculdade } \\
\text { Angel Vianna }\end{array}$ & Estado RJ & Arte & 2 anos \\
\hline PES & $\mathrm{F}$ & $\begin{array}{l}\text { Licenciatura em } \\
\text { Dança }\end{array}$ & Unicamp & Unicamp & $\begin{array}{l}\text { Fac. de } \\
\text { Educação }\end{array}$ & 26 anos \\
\hline
\end{tabular}

Fonte: Elaboração própria a partir dos dados da pesquisa. 
Encontrar professores com formação superior em dança e que atuem com esta área de conhecimento na escola básica representou uma tarefa difícil. Tal fato pode ser justificado em parte porque ainda são poucos os concursos realizados para docentes com essa formação. O professor de dança que consegue se inserir na educação básica, por meio de concurso público, pode ser visto como um pioneiro, sobretudo, porque quando efetivado ainda encontra dificuldades em ofertar aulas de dança ou por falta de espaço adequado ou pela falta de conhecimento da comunidade escolar do que seja o ensino de dança na educação básica. Neste sentido, consideramos que o grupo localizado, embora pequeno, representa sujeitos importantes na compreensão acerca da inserção da dança no currículo da educação básica. Primeiro, porque possuem a formação superior em dança; segundo, porque conseguiram inserir-se na educação básica, por meio de concurso público, e se depararam com o desafio de promover a inserção da dança na escola, seja por meio da disciplina arte, seja pela própria disciplina dança, quando esta existe.

Para fundamentar as análises em didática e formação de professores, temos adotado algumas ideias-chave de Cochran-Smith e Lytle (1999; 2002), Gauthier (2006) e Schön (2000). No que concerne ao currículo, interessou-nos saber como a dança está sendo inserida no currículo escolar, em especial, por meio da perspectiva do multiculturalismo. Para tanto, neste aspecto, nossas análises se apoiaram em estudos de Canen/Ivenicki (2012; 2014). No que diz respeito especificamente à dança, contamos com as contribuições de Marques (2010a; 2011; 2012) e Strazzacappa e Morandi (2010; 2012).

O autor canadense Gauthier (2006) concebe o ensino como a mobilização de vários saberes, que formam uma espécie de reservatório, no qual o professor se abastece para responder às exigências específicas na sua atuação docente. No contexto do ensino de dança podemos problematizar quais saberes são específicos dessa formação, no sentido de reconhecimento dos saberes constitutivos do reservatório do professor de dança e de identificação do que pode contar como saber da ação pedagógica desse professor.

Outra referência importante para nosso estudo são as autoras norteamericanas Cochran-Smith e Lytle (1999). Elas fazem uma distinção entre três concepções de aprendizagem da docência: conhecimento para a prática, 
conhecimento na prática e conhecimento da prática. O conhecimento para a prática parte da perspectiva de que saber mais conteúdo, mais teorias de educação, mais pedagogia, mais estratégias de ensino garante uma prática bem-sucedida. O conhecimento na prática refere-se ao conhecimento em ação. Desse modo, deixa ver a ideia de que a aprendizagem da docência resulta da reflexão de professores a partir das situações práticas. Já o conhecimento da prática, concepção privilegiada pelas autoras, orienta-se pela perspectiva de que o conhecimento que os professores devem ter para ensinar bem decorre de investigação sistemática do ensino, dos alunos e do aprendizado, bem como do conteúdo, do currículo e da escola, em interação com os seus pares.

Considerando que o "na" refere-se aos conhecimentos oriundos da própria docência em ação, nos interessa saber quais conhecimentos são construídos pelos professores de dança em suas aulas. E ainda, ponderando que a terceira abordagem parte do pressuposto de que o professor, ao assumir postura investigativa, teoriza e constrói conhecimento a partir da troca com seus pares, cabe investigar o sentido que o conhecimento da prática assume no ensino de dança, se for o caso.

Schön (2000) ambiciona discutir a forma como profissionais buscam resolver situações incertas, instáveis e singulares e nas quais há conflitos de valor. Ainda que inicialmente o autor não tenha trabalhado com a ideia do professor reflexivo, mas dos profissionais de um modo geral, abriu caminhos para essa concepção entre nós, na perspectiva de refletir antes, durante e depois da prática. Entendemos ser possível, a partir dos conceitos desenvolvidos por Schön (2000), a saber, a epistemologia da prática e o ensino reflexivo, o diálogo com o ensino de dança. A nosso ver, a atuação do professor de dança na escola pode se pautar em um processo de ensino-aprendizagem que parta do pressuposto do ensino reflexivo. Isso não quer dizer que não se valorize o conhecimento científico/teórico/acadêmico (DUARTE, 2003); pelo contrário, não podemos pensar a dança a partir de uma dicotomia entre corpo e mente, razão e intuição, ou entre teoria e prática, pois estar em dança, ensinar dança, dançar, pressupõe uma integração entre todos os níveis e esferas disponíveis para o aprendizado.

Deste modo, investigar concepções e práticas que envolvem o trabalho do professor de dança requer, no nosso entender, considerar o ensino em uma 
perspectiva dialética, sendo modificado pela ação e relação dos sujeitos envolvidos, em torno de contextos situados (CRUZ, 2014). Nessa perspectiva, os saberes para ensinar apontam para a assunção de uma didática crítica e multicultural, que considera a multidimensionalidade e a complexidade no processo de ensinar e aprender.

\section{Os professores e suas visões sobre o ensino de dança na escola}

Pensar sobre a inserção da dança no currículo parece ser um ponto estratégico para iniciar as discussões, visto o processo de escolarização da arte e da dança no Brasil. Conforme apontado anteriormente, embora na atual LDB o ensino de arte seja obrigatório, não podemos esquecer, tal como aponta Barbosa (2016), que durante mais de vinte anos ele foi considerado atividade educativa e que, nesse contexto, as artes visuais prevaleciam sobre as demais áreas do conhecimento artístico (dança, música e teatro).

Com a atual LDB e as mudanças legais ocorridas nos últimos anos, que promoveram a entrada das diferentes áreas do conhecimento artístico no currículo escolar, professores, artistas e pesquisadores têm travado discussões que buscam delinear o que poderia se estabelecer como ensino de arte e de suas áreas, considerando os contextos que envolvem a atual escola pública brasileira. Conhecemos a história, o processo de escolarização da arte e da dança no Brasil, mas, se buscamos de fato inserir a arte e por sua vez a dança no currículo da educação básica, devemos então pensar em propostas que possibilitem fugir da arte isolada em busca de uma arte integrada. Marques (2011) aponta que o conhecimento em arte se articula com o conhecimento através da arte, problematizando e abrindo o leque de possibilidades de relações entre arte, ensino, aluno e sociedade.

Compreendemos ser este um processo lento e complexo, que não demanda apenas iniciativas isoladas de professores ou pesquisadores idealistas, mas também requer maior protagonismo da universidade no que se refere à formação do professor de arte em suas diversas linguagens. Neste sentido, dialogamos com Marques (2011) 
quando ela ressalta o fato de as universidades, muitas vezes, reproduzirem práticas autoritárias e "bancárias"3 do ensino de arte.

Strazzacappa e Morandi (2012) assinala outra polêmica enfrentada na formação do professor de arte: a de que a especificidade e o aprofundamento das áreas que compõem a arte demandam "um conhecimento artístico mais amplo e consistente, e que passa pela essencial experiência (prática) artística. Assim, como possibilitar uma formação plena na qual essas duas funções não se desvinculem?” (STRAZZACAPPA, 2012, p. 85). Além do aspecto da formação, as políticas públicas também devem possibilitar a entrada e permanência desses professores e dessas áreas de conhecimento artístico no currículo. Os gestores, por sua vez, devem ser preparados para compreender a importância e o papel da arte na escola, para além da perspectiva folclórica (CANEN/IVENICKI, 2014).

Compreendemos, portanto, que não basta defender a inserção da dança no currículo sem pensar nas esferas que envolvem o ensino desta e sem delimitar o reservatório de saberes (GAUTHIER, 2006) que envolve a formação e atuação do professor de dança. E ainda, sem compreender de fato as especificidades da dança na escola, as concepções prevalecentes para esse ensino na atualidade e a maneira como ele pode vir a se relacionar com as demais áreas de conhecimento do currículo.

Diante do exposto, o que pensam nossos depoentes? Para iniciar as discussões, tendo em vista dar um pequeno passo a frente, tal como uma dança que se inicia, apresentamos as visões de nossos depoentes sobre a inserção da dança no currículo.

Cinco dos nove professores entrevistados ${ }^{4}$ destacaram que a inserção da dança no currículo pode promover a produção do conhecimento por meio do corpo. De suas falas depreendemos alguns aspectos: i- a dança como uma estrutura de conhecimento; ii- a promoção de uma formação mais abrangente; iii- a dança e a

\footnotetext{
${ }^{3}$ No sentido atribuído por Freire (1997).

${ }^{4}$ A identificação de nossos depoentes ocorrerá com letras maiúsculas as quais representam as três primeiras letras dos Municípios em que lecionam: MES (Mesquita/RJ), NIT (Niterói/RJ) e FRI (Nova Friburgo/RJ). Entretanto, quando formos citar os professores que atuam no Município e no Estado do Rio de Janeiro, optamos por utilizar as siglas das respectivas secretarias, a saber: SME e SEEDUC. A pesquisadora será identificada pela sigla PES.
} 
consciência da corporeidade; iv- a dança como componente de integração na escola. As falas a seguir sustentam o que verificamos:

- A gente precisa [da dança] como uma estrutura de conhecimento (MES).

- Então você vai chamá-los para uma proposta que é intelectual em cima daquilo, para despertar uma cognição, despertar uma abstração (SME).

- Necessário para a formação, principalmente no ensino básico, para formação completa, ou para que a gente possa pensar numa formação que seja mais abrangente. Que não se limite somente ao conteúdo do quadro, do giz, e do que está escrito (FRI).

- Eu acho que é importante nós começarmos a trabalhar com os alunos a partir de outros níveis de apreensão do conhecimento. [...] A dança, além da questão artística, educacional, ela deveria estar também enquanto trabalho de consciência corporal, juntamente com outras disciplinas importantes em qualquer curso, âmbito ou idade. Esse é o caminho para não termos uma educação tão bancária e mecanizada (FAETEC1).

- Ela é uma ferramenta de integração, de conhecimento por uma via prática, corporal, entretenimento. Os jovens gostam muito de dançar! (FAETEC2).

Diante das falas, verificamos que há uma defesa da dança, no sentido de garanti-la presente no currículo escolar como um espaço que promova o ensino e a aprendizagem para além da perspectiva formativa conteudista que pode abafar uma atuação reflexiva (SCHÖN, 2000). Coadunamos com as falas dos professores, buscando compreender o ensino de dança na escola como espaço de produção do conhecimento por meio do movimento expressivo. Tecemos nossa crítica no sentido de que, embora estejamos em uma sociedade contemporânea, na qual nossos corpos são estimulados a todo momento por informações de várias naturezas (sensoriais, visuais, sonoras, dentre outras), a educação e, por sua vez, a forma de ensinar, ainda se pautam na supremacia da cognição, no saber da tradição pedagógica (GAUTHIER, 2006), no ensinar por meio da exposição do professor, da leitura de textos, enfim, o corpo acaba ficando subjugado neste processo. Não estamos aqui fazendo a defesa de uma área de conhecimento artístico em detrimento de outras, apenas expondo que existem outras formas de ensinar e aprender que talvez possam ser mais adequadas às demandas da sociedade atual, tal como defende o entrevistado FAETEC1:

- E o corpo é um nível essencial, que tem sido pouco explorado para apreensão desse conhecimento. Eu penso que todas as matérias deveriam trabalhar de alguma forma 
com a apreensão do conhecimento a partir do corpo. Isso é uma questão que a gente precisa buscar. A dança ela entra nesse lugar como um caminho, um viés que precisa, é necessário, é essencial que esteja. Apesar de vermos que isso não é muito valorizado. E essa questão da dança entrar nos currículos, já é uma conquista, de anos e anos de lutas de profissionais, e de pessoas que vivem a dança e vivem o corpo (FAETEC1).

Discutir a inserção da dança no currículo e a produção do conhecimento por meio do corpo evoca o papel central ocupado pelo professor de dança e os diferentes aspectos que abrangem sua formação. Dentre as concepções de docência, a epistemologia da prática (SCHÖN, 2000) ajuda-nos a pensar em proposições para a formação do professor de dança, a qual poderia abarcar a dimensão reflexiva do ensino. Não se pode pensar em um ensino que ocorra por meio de uma via prática corporal, que promova a consciência da corporeidade, como evidenciam os depoentes, se a formação desse professor se dá por um viés formativo conteudista, onde prevalece o saber disciplinar (GAUTHIER, 2006) ou o conhecimento para a prática (COCHRAN-SMITH; LYTLE, 1999). Em ambas as perspectivas há uma ênfase no pressuposto de que para ensinar basta o professor dominar o conhecimento da matéria a ser ensinada. Neste sentido, ele não é o construtor desse conhecimento, mas o acessa em sua formação acadêmica. A epistemologia da prática não nega a teoria, mas afirma a teoria que se constrói com a prática. No caso do ensino de dança, defendemos que ele parta dos saberes específicos da dança e que esse processo ocorra por meio da reflexão, da ação, como aquilo que está expresso na artesania da prática (SCHÖN, 2000).

Marques (2011) defende que o ensino de dança na escola ocorra a partir da interseção entre três esferas de conhecimento, quais sejam: textos da dança (improvisação, composição e repertórios); subtextos da dança (elementos estruturais da dança, elementos sócio-afetivo-culturais); contextos da dança (história, música, cinesiologia, antropologia, anatomia, estética, crítica). Essas três esferas se interligam e encontram em seu centro o contexto ampliado dos alunos. Entretanto, a autora ressalta que, nesta proposição, ao professor cabe outro tipo de atitude, que se assemelha mais à de um pesquisador com postura investigativa (COCHRAN-SMITH; LYTLE, 2002) do que à de professor do tipo transmissor de conhecimento, conforme apontado anteriormente. 
A inserção da dança no currículo, de acordo com três dos nove depoentes, possibilita trabalhar questões sociais e humanas. Neste sentido, os entrevistados destacaram alguns aspectos que podem ser trabalhados nas aulas de dança, tais como: i- trabalhar questões mais humanas e sociais, pois permite minimizar a violência e promove a questão da coletividade; ii- trabalhar contextos éticos e estéticos pensando na vivência coletiva; iii- proporcionar espaço para a reflexão do corpo como paradigma social. Vejamos o que nos dizem os depoentes a esse respeito:

- Eu acho que ela [a dança] tem uma função social na escola, que está para além do que a gente consegue regulamentar. As crianças estão o tempo inteiro se expressando pelo corpo. Você ter um espaço onde você possa organizar isso é um desafio, e é ao mesmo tempo, um campo de libertação. A questão da violência também é muito forte, então, neste sentido, quando eles estão dançando eles não estão brigando, passam a ter uma postura de mais união, então têm essas questões mais humanas e sociais (SME).

- Então às vezes uma situação que é hipotética, ou que está no plano da imaginação, você consegue fazer com que ela se concretize no corpo, na dança. Então, eu entendo que o lugar da dança na escola é produzir conhecimento, produzir sensações, trabalhar contextos éticos e estéticos, pensando na vivência coletiva (FRI).

- Eu acho importante [o ensino de dança] pelo olhar para o corpo que é um grande paradigma social. E as pessoas conhecem pouco do seu próprio corpo. A questão da movimentação, a questão de se conhecer. Eu acho importante a questão da sociabilidade que ela promove. A gente está num país altamente dançante, e que a dança dentro da escola é uma ferramenta de integração, de trazer o aluno para perto (FAETEC2).

Compreendemos que as questões apontadas pelos depoentes não são exclusivas do ensino de dança. Entretanto, devido à natureza desta área do conhecimento artístico, suspeitamos, assim como eles, ser a dança um campo fértil para enfatizá-las, principalmente porque entendemos serem demandas reais da escola contemporânea.

Os aspectos destacados nos excertos acima representam questões caras e pertinentes ao ensino de dança. Tal como tivemos chance de discutir (BATALHA; CRUZ, 2019), o próprio ato de dançar pressupõe uma exposição que coloca em xeque questões que possibilitam discutir ideais de corpos e de gestos impostos pela sociedade, em geral arraigados e propagados pelos meios de comunicação. Marques (2010a) ressalta que a escola teria o papel de instrumentalizar e de construir conhecimento em/por meio da dança com seus alunos, pois ela é, assim como outras 
áreas, forma de conhecimento, elemento essencial para a educação do ser social. Sabemos que esse argumento não é nada inovador, entretanto, no caso da dança, esse conhecimento, esse fazer não está dissociado do corpo, que é a própria dança. Essa autora ajuda-nos a compreender a contribuição da dança na educação como "educar corpos que sejam capazes de criar pensando e re-significar o mundo em forma de arte” (MARQUES, 2010b, p. 24). Neste sentido, entendemos a dança como arte engajada com o aspecto cognitivo e não somente com o afetivo. Deste modo, o corpo que dança e o corpo na dança são fontes de conhecimento sistematizado e transformador. Por meio dos nossos corpos, apreendemos regras e conceitos vigentes na sociedade. Raramente somos incentivados a arriscar novos movimentos, posturas; via de regra, somos levados à homogeneização.

Assim, acreditamos que, nas aulas de dança, questões sociais e humanas podem ser relativizadas, como apontam os entrevistados. Conceitos éticos e estéticos que permeiam tão fortemente nossas visões de corpos e de danças podem ser desconstruídos, problematizados. De acordo com Marques:

Em nossas salas de aula, o que estaríamos ensinando sobre hierarquia e poder quando nos colocamos na frente dos alunos e, virados de costas, mandamos que simplesmente nos sigam? Ou ainda, que mensagens estariam ocultamente contidas no fato de o professor privilegiar as danças populares em detrimento do repertório pessoal de movimento de cada aluno (mesmo que culturalmente construído)? (MARQUES, 2010a, p. 27).

A citação é reveladora, pois denuncia que, em alguns casos, as aulas de dança podem reproduzir posturas, ou mesmo estilos de dança, sem criticidade. As atitudes carregam um sentido muito forte no ato de ensinar; querendo ou não, os professores são referência para os alunos. Deste modo, compreendemos que o ensino de dança na escola, embora possa ser rico, possibilitando trabalhar questões pertinentes e atuais, se esvaziado de uma proposta de ensino/aprendizagem alicerçada em pressupostos que incluam a reflexão e a criticidade, pode correr o risco de se engessar e permanecer no isolamento.

O ensino de dança na escola, de acordo com três dos nove depoentes, possibilita também trabalhar questões multiculturais. Um depoente destaca que a dança sempre esteve presente na escola, mesmo que em eventos pontuais. No seu dizer: 
- Porque a gente dialoga com a dança o tempo todo, porque ela sempre esteve presente na escola, ou na festa junina, ou no dia do folclore, e esse espaço é um espaço do professor de dança (MES).

Esta fala nos remete à perspectiva folclórica presente no multiculturalismo (CANEN/IVENICKI, 2012), visto que nela as questões da pluralidade cultural aparecem em estratégias pontuais, conforme se observa no excerto acima. No que se refere ao multiculturalismo, destacamos também a perspectiva crítica, que articula a visão folclórica à discussão sobre as relações de desigualdades e analisa as construções históricas dos preconceitos, das discriminações e da hierarquização cultural, e a perspectiva pós-colonial, que busca analisar na linguagem a construção dos discursos curriculares e pensar como as diferenças têm sido construídas, procurando "descolonizar o currículo".

Diante do exposto, filiamo-nos à perspectiva pós-colonial, pois nela partimos do pressuposto de que as categorias discursivas não somente são construídas discursivamente, como também acabam por deixar de lado processos relacionais que produzem subculturas e identidades híbridas. Deste modo, cotejamos o ensino de dança, indo contra o aspecto utilitarista e a favor da desconstrução dos discursos que buscam homogeneizar o currículo e, por sua vez, o ensino de dança.

A próxima fala, assim como a citação anterior, converge para a perspectiva folclórica presente no multiculturalismo:

- Eu acho que quando ela for regulamentada, a obrigatoriedade vai fazer com que os diretores reconheçam também. Tirando desse lugar que a dança serve para a apresentação de final de ano, dessas apresentações utilitárias de datas comemorativas, a dança serve para as pessoas verem que estamos produzindo alguma coisa artística na escola, quando ela entrar no currículo talvez as pessoas não questionem mais (SEEDUC1).

Conforme temos argumentado, há certo desconforto no que se refere ao lugar destinado à dança na escola. O problema não é a presença da dança em datas comemorativas; o problema ocorre quando este ensino fica restrito a eventos pontuais. Para Marques (2010a) a escola é um lugar privilegiado para que se possa aprender dança com qualidade, compromisso, amplitude e responsabilidade, por isso, não pode continuar sendo sinônimo de festinhas de fim de ano. 
O professor, ao propor trabalhar em suas aulas de dança questões que envolvam a pluralidade cultural, precisa atentar para que as danças propostas não sejam homogeneizadas. Dito de outro modo, se os professores ensinam na escola danças populares, sem promover uma reflexão sobre os modos de ser que estão implícitos naquela movimentação, elas poderão ser tão estrangeiras ou alienantes quanto as danças promovidas pela mídia. O fato de trabalhar temas populares não garante que a apropriação do movimento ocorra por meio de reflexão e criticidade. Para isso nos ajuda Marques quando diz que:

Raramente paramos para analisar, discutir, refletir e contextualizar as danças populares, tanto em suas estruturas coreológicas, coreográficas ou temáticas. Que relações de gênero estão presentes nas quadrilhas quando homens são separados em fila das mulheres? Que posturas éticas estão sendo ensinadas no jogo da capoeira? Malícia? Malandragem? Que papel de mulher está implícito no rebolado faceiro do carimbó? Que visão de religiosidade está presente no maracatu? Que papéis sociais estão sendo trabalhados no Lundu Colonial? Mas além: o que tudo isto tem a ver com o Brasil/juventude de hoje? (MARQUES, 2010a, p. 161).

Essas questões parecem pertinentes se buscamos um ensino de dança crítico e condizente com a sociedade contemporânea. Do contrário, corremos o risco de mantermo-nos na perspectiva folclórica, assim como criticou o depoente SEEDUC1.

No âmbito da mesma questão, notamos um aspecto positivo no que se refere à pluralidade cultural, como podemos depreender na fala a seguir:

- O que a gente tem que é nosso? São as danças brasileiras. Então, como fazemos o trabalho da dança na escola dialogar com o que os próprios jovens e as crianças trazem? Então eu falei para os licenciandos: - Vejam com os alunos o que eles trazem, as memórias das famílias deles. Foi muito interessante! As danças, a tradição das canções, das brincadeiras, nós começamos a ver que a mesma brincadeira tem nomes diferentes dependendo do lugar, então com tudo isso fomos criando um repertório, um material para dialogar com visões de dança na escola e visões de corpos, esses corpos presentes e essa diversidade (PES).

Como se pode notar, neste trecho há uma ênfase na valorização da cultura popular e na maneira como esse elemento pode vir a contribuir para que o ensino de dança na escola se estabeleça a partir do patrimônio cultural e da diversidade que ele representa. Essa mesma perspectiva aferimos na fala de outro depoente:

- Os avôs, as avós desses meninos, provavelmente eles vêm de uma cultura popular, eles não vêm de uma cultura erudita. E principalmente os alunos, eles estão 
massificados! Eles estão completamente cheios da cultura de massa. Por que eu estou evidenciando danças populares? Justamente para promover esse resgate dos valores, não posso dizer valores, mas de coisas que estão adormecidas, que estão neles, porque aí é hereditário, e que podem ser resgatadas com os pais, enfim, com o entorno. Acho que isso pode ser um canal bem interessante, de profundidade, de não trabalhar só o conteúdo isolado, do contexto deles, e também dialogando com as outras disciplinas, é assim que eu visualizo (SEEDUC1).

Concordamos com nossos depoentes (PES e SEEDUC1), demarcando que, diante do mosaico que representa a cultura popular brasileira, a dança na escola não pode isentar-se de promover um espaço onde essa prática possa ocorrer. Defendemos que esse processo esteja, sempre que possível, imbuído de reflexão, no sentido de contextualizar e desconstruir os discursos homogeneizantes, conforme aponta o multiculturalismo pós-colonial.

Até o momento, foram enfatizados os aspectos a favor da dança, no sentido de tornar potente a sua inserção no currículo da educação básica. A seguir, será discutido o que os entrevistados apontaram como fatores estruturantes e limitadores para que este ensino se estabeleça.

Dos nove depoentes, três destacaram dificuldades estruturais para que o ensino de dança se estabeleça na escola. De suas falas emergiram questões como: iespaço físico precário e inadequado; ii- turmas com elevado número de alunos para a prática da dança; iii- arquitetura escolar idealizada para o aluno ter aula teórica. Essas questões ficaram explícitas nas falas a seguir:

- Eu penso que a dança na escola é necessária, mas infelizmente a gente não tem auditório, a gente não tem uma sala fechada sem carteiras, não precisa nem ter barra nem espelho, sabe? Nem faço questão, mas que tenha um piso sem nada no local em que a gente possa se movimentar, que ninguém esteja olhando, que o rádio seja ouvido. E que o rádio não atrapalhe quem está do lado, então isso não existe! Essa concepção de dança na escola, hoje, para as escolas que a gente tem na rede, e até muitas particulares, é meio utópica não é? (NIT).

- A estrutura da escola é feita para ter aula teórica. Pouquíssimas escolas têm a estrutura que você precisa. Quiçá um lugar que você possa tirar o sapato, dançar. E outro grandíssimo desafio é o número de alunos nas turmas. Tem turmas que têm quarenta e cinco alunos! Para você trabalhar o processo prático de dança, quando você tem que passar o conteúdo e todo mundo tem que acompanhar é uma dispersão muito grande. Bem difícil de trabalhar assim. (SEEDUC1).

- E a grande dificuldade é que as escolas não têm espaço físico adequado. O espaço de hoje não é propício para atividades artísticas. É uma arquitetura, uma engenharia, muito datada. São escolas bonitas, mas que são formatadas para que o aluno fique 
sentado na sala de aula, naquela relação que não dá mais conta do que é o mundo hoje (SEEDUC2).

Observamos nas falas visões negativas no que se refere ao espaço físico destinado à dança na escola, dificultando sua prática. Infelizmente, sabemos que essa é uma realidade das escolas brasileiras. Com raras exceções, as escolas não têm salas devidamente preparadas para receber as diversas áreas de conhecimento artístico. Um espaço amplo, livre, com piso adequado parece ser o desejo de todo professor de dança. Para que ocorra a prática da dança deve haver um espaço onde os alunos sintam-se livres, possam fazer barulho e tenham privacidade para se expressar. Compreendemos ser este um grande desafio para os professores, entretanto, a questão estrutural na educação tangencia inclusive o âmbito acadêmico, como se pode verificar na fala a seguir:

- E têm cursos que têm um corpo docente bacana, mas não têm infraestrutura. Eu fui recentemente convidada para uma banca, na hora que eu cheguei e vi a sala de aula que eles têm para fazer aula de dança, com piso que tem lasca de madeira saindo, sala com vidro quebrado, daí entra vento, aí você fala assim: - A universidade sucateada! E tem o outro lado, que são cursos de licenciatura em dança no Brasil que abriram pelo Reuni, têm uma sala maravilhosa, porque daí eles investiram no prédio. Então tem o prédio com pé direito alto, piso de madeira, som, mas não tem corpo docente. Por quê? Porque abrem concurso e ninguém quer ir para lá! (PES).

Neste excerto, observamos que ainda há muito a fazer. No que se refere às políticas públicas destinadas à educação, avançamos, mas ainda estamos longe do que gostaríamos de ver prevalecer na realidade educacional brasileira. Se formos aguardar mudanças na realidade estrutural das escolas públicas, é possível que o ensino de dança nunca se estabeleça; entretanto, podemos buscar, em cada realidade, uma possibilidade de melhoria. Neste caso, a comunidade escolar e, por sua vez, os gestores ocupam papel decisivo nesse processo, como notamos na fala a seguir:

- Na época que eu trabalhava especificamente com os alunos de dança, eu sentia sempre que eles estavam muito revoltados. Os licenciandos diziam assim: - Ah! Cheguei lá na escola e a diretora não me escutava. O supervisor reclamou do barulho! Sempre revoltados. Eu falava assim: - Gente vocês estão chegando com uma coisa que é estranha, que faz bagunça, que tira a carteira do lugar, vocês não precisam chegar com o 'pé no peito'. Vocês têm que seduzir e conquistar. Então, vocês vão chegar com o sorriso no rosto, vão cumprimentar a moça da cantina, o bedel que fica lá no corredor, porque na hora que vocês forem montar uma apresentação é com essas pessoas que vocês vão contar, para limpar o palco, esticar 
o pano...vocês têm que tratar bem, chegar e falar assim: - Gente, o que eu faço é a coisa mais bacana que tem no mundo! Eu adoro o que eu faço! E aí eles começaram a mudar a postura (PES).

Como se pode verificar, a inserção da dança no currículo representa ainda um claro e grande desafio, mesmo que se reconheça que o ensino de dança favorece discutir a produção do conhecimento por meio do corpo e possibilita uma formação mais abrangente, que inclua o corpo e o movimento para a apreensão e construção do conhecimento e aspectos contextuais e estruturais da organização e gestão da escola, incluindo a sua concepção e prática curricular, que desafiam os professores da área. A possibilidade de trabalhar questões sociais e humanas no ensino de dança, de acordo com as falas dos depoentes, aponta a necessidade de desconstrução de conceitos éticos e estéticos arraigados em nossa sociedade, atuando favoravelmente no combate à violência e na promoção da vivência coletiva. Diante disso, como não reconhecer a importância, a necessidade e, mais que isto, a viabilidade do ensino de dança na escola? Nesse contexto emergem questões multiculturais presentes neste ensino, prevalecendo uma perspectiva folclórica e, no nosso entender, reducionista, porque lida com a pluralidade em momentos pontuais e não como uma dimensão constitutiva da formação humana e consequentemente integradora da prática curricular escolar. Por isto, nossa defesa da perspectiva multicultural pós-colonial, que advoga pela desconstrução dos discursos homogeneizantes que permeiam o currículo escolar. Finalmente, no que tange às dificuldades estruturais, notamos que ainda há muito a ser feito para favorecer o ensino das diferentes áreas de conhecimento artístico na escola básica pública, embora possamos vislumbrar formas de resistência, em que pese a importância e a ação coletiva da comunidade escolar.

\section{Considerações finais}

Concluímos este relato tecendo algumas considerações que sumarizam as principais contribuições do estudo desenvolvido. Embora o Brasil seja considerado um país dançante, vibrante e corporal (MARQUES, 2010a) e a dança na escola desperte o interesse dos alunos, pois, via de regra, eles gostam de se expressar por meio da dança, ainda assim, ela permanece como uma área de conhecimento artístico 
pouco debatida em âmbito escolar e acadêmico. Suas possibilidades na escola, em geral, são desconhecidas pela própria comunidade escolar, dificultando ainda mais a sua inserção no currículo. Diante deste panorama pouco favorável, e por isso mesmo desafiador, procuramos reunir as questões que se fazem desafios, julgadas mais pertinentes em torno do objetivo da pesquisa - compreender como professores com formação superior em dança (bacharel ou licenciado), que atuaram ou estão atuando na educação básica pública, concebem o ensino de dança e, além disso, o que fazem (se fazem) a favor da sua inserção no currículo escolar.

O primeiro grande desafio diz respeito à identificação dos sujeitos da pesquisa (professores graduados em dança que estejam atuando com este ensino na escola básica pública). Embora possa parecer pouco relevante, o processo de captura desses professores coloca em evidência uma questão determinante para a inserção da dança no currículo escolar: a falta de profissional certificado para trabalhar com dança na escola representa, no nosso entender, um entrave para que as aulas de dança sejam oferecidas com o investimento que merecem. Quando o professor de dança consegue se inserir nas redes de ensino, aquelas que porventura já estão aceitando esses professores em suas escolas, sua atuação causa/gera dúvidas sobre como se estabelecer. Constatamos que a falta de informação sobre a natureza da dança na escola, ou mesmo a falta de espaço adequado para as aulas, em alguns casos abafa a atuação desse professor. O docente se vê, em geral, conduzido a exercer seu ofício em abordagem polivante, ou até reduz sua atuação a visões utilitárias da dança, em momentos pontuais, para que "as pessoas vejam que estamos produzindo alguma coisa artística na escola” (SEEDUC1).

O segundo desafio emerge do processo de inserção da dança no currículo. Ao analisarmos a visão dos professores sobre isto, deparamo-nos com quatro aspectos: i- produção de conhecimento por meio do corpo; ii- possibilidade de trabalhar questões sociais e humanas; iii- questões multiculturais presentes na inserção da dança no currículo; vi- dificuldades estruturais para o ensino de dança na escola. Os dados revelaram que a inserção da dança no currículo ainda é um evidente desafio para os professores de dança. Mesmo que este ensino promova a produção do conhecimento por meio do corpo, aspectos contextuais e estruturais da organização e gestão da escola, assim como sua concepção e prática curricular, desafiam os professores de 
dança. A possibilidade de trabalhar questões sociais e humanas permite que a dança possa vir a minimizar a violência e, ainda, atuar na desconstrução de conceitos éticos e estéticos destinados ao corpo. Diante do exposto, indagamos: como não garantir este ensino na escola? Questões multiculturais presentes na inserção da dança no currículo foram destacadas pelos depoentes, em especial a perspectiva folclórica (CANEN/IVENICKI, 2012), que reduz a pluralidade cultural a momentos pontuais, fato que contribui para fazer prevalecer um ensino de dança centrado em uma visão utilitária. Defendemos que as questões que envolvem a pluralidade cultural, assim como gênero, raça e etnia, devem ser trabalhadas ao longo do período escolar, visando uma dimensão constitutiva da formação humana e consequentemente integradora do currículo. Os dados apontaram ainda para as dificuldades estruturais para o ensino de dança na escola, que impedem que a dança possa ser oferecida com qualidade e segurança.

Finalizando, voltamos o foco para os sujeitos deste estudo. A pesquisa só foi possível porque conseguimos localizar um grupo minoritário, mas representativo e, mais que isto, pioneiro. Nossos investigados estão em diferentes instituições de ensino, delineando e construindo um campo. Ainda que a dança no currículo da escola básica esteja em posição frágil, verificamos que avanços foram alcançados. O aumento no número de cursos, a presença da dança em documentos oficiais e a inserção dos professores nas diferentes instituições de ensino certamente contribuirão para a afirmação da dança no currículo escolar. Apontamos também a necessidade de novos estudos que tragam à cena a dança. Salientamos ainda que o poder público deve garantir a entrada desses professores nas escolas, assim como a inserção da dança no currículo enquanto área de conhecimento artístico. Deste modo, acreditamos que a dança ganhará visibilidade, se desvelando e incorporando na escola suas infinitas possibilidades para uma formação mais humana e integradora.

\section{Referências}

BATALHA, C. S.; CRUZ, G. B. A didática e a docência no contexto da licenciatura em dança. Educação Unisinos, São Leopoldo, v. 22, n. 4, p. 288-297, out./dez. 2018.

BATALHA, C. S.; CRUZ, G. B. Ensino de dança na escola: concepções e práticas na visão de professores. Educaşão, Artes e Inclusão, Florianópolis, v. 15, n. 1, p. 72-97, jan./mar. 2019. 
BARBOSA, A. M. Arte-Educação no Brasil. 7. ed. São Paulo: Perspectiva, 2016.

BRASIL. Ministério da Educação e Cultura. Lei de diretrizes e bases da educação nacional Lei no 9394/96, de 20 de dezembro de 1996. Estabelece as diretrizes e bases da educação nacional. Brasília: MEC, 1996.

BRASIL. Ministério da Educação. Lei no 13.278, de 2 de maio de 2016. Fixa as diretrizes e bases da educação nacional, referente ao ensino da arte. Brasília: MEC, 2019. Disponível em: www2.camara.leg.br/acesso em: abril, 2019.

CANEN/IVENICKI, A. Currículo e Multiculturalismo: reflexões a partir de pesquisas realizadas. In: SANTOS, L. L. C. P.; FAVACHO, A. M. P. (Orgs.). Políticas e Práticas Curriculares: desafios contemporâneos. Curitiba: CRV, 2012. p. 237-250.

CANEN/IVENICKI, A. Currículo para o desafio a xenofobia: algumas reflexões multiculturais na educação. Revista Conhecimento e Diversidade, v. 6, n. 11, p. 89-98, 2014. Disponível em: $<$ https://revistas.unilasalle.edu.br/index.php/conhecimento_diversidade/article/view/174 2/>. Acesso em: maio 2019.

COCHRAN-SMITH, M.; LYTLE, S. L. Relationships of knowledge and practice: Teacher learning in communities. Review of research in education, Washington, DC, v. 24, n. 1, p. 249305, Jan. 1999.

COCHRAN-SMITH, M.; LYTLE, S. L. Teacher Learning Communities. In: GUTHRIE, J. (Ed.). Encyclopedia of Education. 2nd Edition. New York: Macmillan, 2002.

CRUZ, G. B. et al. Ensino de Didática: entre recorrentes e urgentes questões. Rio de Janeiro: Quartet, 2014.

DUARTE, N. Conhecimento tácito e conhecimento escolar na formação do professor (por que Donald Schön não entendeu Luria). Educação e Sociedade, Campinas, v. 24, n. 83, p. 601625, 2003. Disponível em: <http://www.scielo.br/pdf/\%0D/es/v24n83/a15v2483.pdf:/>. Acesso em: maio 2019.

FREIRE, P. Pedagogia da autonomia: saberes necessários à prática educativa. 20. ed. São Paulo: Paz e terra, 1997.

GAUTHIER, C. et al. Por uma teoria da pedagogia: pesquisas contemporâneas sobre o saber docente. 2. ed. Ijuí: Editora Unijuí, 2006.

MARQUES, I. A. Dançando na escola. 5. ed. São Paulo: Cortez, 2010a.

MARQUES. Ensino de dança hoje - textos e contextos. 6. ed. São Paulo: Cortez, 2011.

MARQUES. Linguagem da dança: arte e ensino. São Paulo: Digitexto, 2010b.

MARQUES. Oito razões para ensinar dança na escola. In: ICLE, G. (Org.). Pedagogia da Arte: Entre Lugares da Escola. Porto Alegre: Editora da UFRGS, 2012. p. 57-72.

MILLS, W. C. A Imaginação Sociológica. 6. ed. Rio de Janeiro: Zahar Editores, 1982. 
MINAYO, M. C. (Org) Pesquisa Social. Teoria, método e criatividade. 33. ed. Petrópolis, RJ: Vozes, 2013.

SCHÖN, D. A. Educando o profissional reflexivo: um novo design para o ensino e a aprendizagem. Porto Alegre: Artes Médicas Sul, 2000.

SOTER, S. C. Saberes Docentes para o Ensino de Dança: relação entre saberes e formação inicial de licenciados em dança e em educação física que atuam em escolas da Rede pública do Rio de Janeiro e da Região Metropolitana. 2016. 266 f. Tese (Doutorado em Educação) Faculdade de Educação. Universidade Federal do Rio de Janeiro, Rio de Janeiro, 2016.

STRAZZACAPPA, M. A Tal Dança Criativa: afinal, que dança seria? In: TOMAZZONI, A. et alii. Algumas perguntas sobre dança e educação. Joinville: Nova Letra, 2010. p. 39-46.

STRAZZACAPPA, M.; MORANDI, C. Entre a Arte e a Docência: a formação do artista da dança. 4. ed. Campinas: Papirus, 2012. 